\title{
Sağlıklı Yetişkinler için Sedanter Davranış Anketinin Türkçe Kültürel Adaptasyonu ve Güvenirliği
}

\section{The Turkish Cultural Adaptation and Reliability of the Sedentary Behavior Questionnaire for Healthy Adults}

\author{
Begüm Kara Kaya ${ }^{1,2^{*}}$, Ayșe Zengin Alpözgen ${ }^{3}$ \\ ${ }^{1}$ Biruni Üniversitesi, Sağlık Bilimleri Fakültesi, Fizyoterapi ve Rehabilitasyon Bölümü, İstanbul, Türkiye. \\ ${ }^{2}$ İstanbul Üniversitesi-Cerrahpaşa, Lisansüstü Eğitim Bilimleri Enstitüsü, Fizyoterapi ve Rehabilitasyon Doktora \\ Program1, İstanbul, Türkiye. \\ ${ }^{3}$ İstanbul Üniversitesi-Cerrahpaşa, Sağlık Bilimleri Fakültesi, Fizyoterapi ve Rehabilitasyon Bölümü, İstanbul, \\ Türkiye. \\ e-mail: bkara@biruni.edu.tr, azengin@istanbul.edu.tr \\ ORCID: 0000-0003-4236-6679 \\ ORCID: 0000-0003-0436-1164 \\ *Sorumlu yazar/ Corresponding Author: Begüm Kara Kaya \\ Gönderim Tarihi / Received: 02.05.2021 \\ Kabul Tarihi / Accepted: 29.06.2021 \\ DOI: $10.34087 /$ cbusbed. 931301 \\ $\ddot{O} z$
}

Giriş ve Amaç: Sedanter Davranış Anketi’nin (SDA), 18-64 yaş arası sağlıklı bireylerde Türkçe kültürel adaptasyonunu ve güvenirlik çalışmasını yapmaktır.

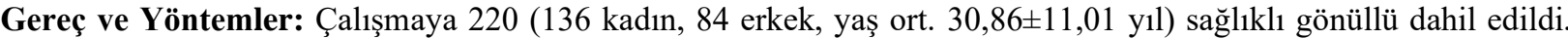
Hafta içi (HI) ve sonu (HS) olmak üzere toplamda 22 maddeden oluşan SDA'nın Türkçeye adaptasyonu 5 aşamada gerçekleştirildi: 1)İki kişi tarafından İngilizceden Türkçeye çeviri, 2)Ön çevirilerin karșılaştırılması ve düzenlenmesi, 3)Düzenlenen anketin Türkçeden İngilizceye çevrilmesi, 4)Çevirinin orijinal anketle karşılaştırılması, anketlerin harmonizasyonu, 5)Beş kişiye pilot uygulama ile anketin nihai hale getirilmesi. Benzer ölçek olan Uluslararası Fiziksel Aktivite Anketi kısa formu (UFAA-KF) oturma bölümüyle SDA arasında Pearson korelasyon bakılarak, anketin yapısal geçerliliği test edildi. Yedi gün arayla doldurulan SDA'nın güvenirliği, \%95 güven aralığında (CI) test-retest ve iç tutarlılık katsayıları (ICC) ile değerlendirildi. Verilerin analizinde SPSS 24.0 kullanıld1.

Bulgular: Yapısal geçerlik değerlendirildiğinde SDA-Hİ, HS ve toplam süreler ile UFAA-KF oturma süresi arasindaki korelasyon sirasiyla, $r=0,254, \mathrm{p}<0,001 ; \mathrm{r}=0,231, \mathrm{p}=0,001 ; \mathrm{r}=0,265, \mathrm{p}<0,001$ olarak hesaplandi. Anketin Cronbach alfa katsayısı 0,588 (\%95 CI; 0,505-0,663); ICC 0,83 (\%95 CI: 0,78-0,87) değerinde bulundu. SDA'nın iki ölçümü arasındaki güvenirliği incelendiğinde "Oturarak telefonla konuşmak" maddesi hariç tüm maddelerin ICC değerlerinin ve korelasyon katsayılarının istatistiksel açıdan orta-mükemmel arasında olduğu tespit edildi $(p<0,05)$. Sonuç: SDA, 18-64 yaş arası sağlıklı erişkinlerde kolayca uygulanabilen, güvenilir ancak UFAA-KF oturma süresi ile zayıf korelasyonu olan, kapsamlı bir ankettir. SDA ile sedanter davranışların farklı alanları ve tipleri hakkında daha net bilgiler elde edilebilirken, anketin kullanımı farklı popülasyonların spesifik olarak araştırılabilmesine ve uygun müdahalelerin planlanabilmesine olanak sağlar.

Anahtar Kelimeler: Fiziksel inaktivite, Güvenirlik, Geçerlik, Sağlık, Sedanter yaşam.

\section{Abstract}

Objective: To adapt the Sedentary Behavior Questionnaire (SBQ) to Turkish and investigate its reliability in healthy individuals aged 18-64.

Materials and Methods: Two hundred twenty volunteers (136 females, 84 males, mean age $30.86 \pm 11.01$ years) were included. The adaptation of SBQ containing total 22 items including weekdays (WD) and weekends (WE), was carried out in 5 stages: 1)Translation from English to Turkish, 2)Comparison and editing of pre-translations, 3)Translation of questionnaire from Turkish to English, 4)Comparison of the translation with the original 
questionnaire, harmonization of questionnaires, 5)Finalization of the questionnaire with pilot application for five people. The construct validity was tested with Pearson correlation between SBQ and International Physical Activity Questionnaire-Short Form (IPAQ-SF) sitting section. The SBQ data collected twice in 7 days interval for reliability at $95 \%$ confidence interval (CI) with test-retest and internal consistency coefficient (ICC). SPSS 24.0 was used for analysis.

Results: The Pearson correlations between SBQ-WD, WE, total time and IPAQ-SF sitting time were, respectively, $\mathrm{r}=0.254, \mathrm{p}<0.001 ; \mathrm{r}=0.231, \mathrm{p}=0.001 ; \mathrm{r}=0.265, \mathrm{p}<0.001$. The cronbach alpha of questionnaire was 0.588 (95\% CI; $0.505-0.663$ ); ICC was 0.83 (95\% CI: $0.78-0.87$. The ICC and correlations for reliability were significant from moderate to perfect for all items except for "Sitting and talking on the phone" $(\mathrm{p}<0.05)$.

Conclusion: The SBQ is reliable, comprehensive, easily applicable questionnaire to healthy adults, but has poor correlation with IPAQ-SF. While more clear information about different domains and types of sedentary behaviors can obtained with SBQ, its use allows investigating different populations and planning appropriate interventions for different populations.

Keywords: Sedentary life, physical inactivity, health, reliability, validity

\section{Giriş}

Sedanter davranışlar, uyanıkken oturma veya uzanmayı içeren, genellikle 1.5 metabolik eşdeğerden daha düşük enerji harcamasına neden olan işler olarak tanımlanır [1]. Gelişmiş toplumlardaki insanlar çalışmak, seyahat etmek veya boş zaman geçirmek (televizyon (TV) izlemek vb.) gibi yaşamın temel alanlarında giderek artan sürelerde sedanter davranışlar sergilemektedir [2]. Yapılan çalışmalar kişiler tarafından bildirilen oturma süreleriyle kronik hastalık ve mortalite riski arasında pozitif ilişki olduğunu göstermiştir [3-5]. Yaklaşık 600.000 yetişkinin dahil edildiği bir metaanalizde, gün içinde oturarak harcanan her saatin tüm nedenlere bağlı ölüm oranında \%2'lik bir artış meydana getirdiği bildirilmiştir [6].

Son yıllarda toplumların ve şehirlerin gelişim düzeylerine paralel olarak artan sedanter yaşam tarzı, sağl1k üzerinde olumsuz etkilere sahip olması ve mortalite riski nedeniyle önemli bir halk sağlığ problemidir. Sosyokültürel gelişmeler ve değişimlerle birlikte kısalan yürüme mesafeleri ve süreleri, azalan ev dışı aktivitelere katılım gibi sebeplerle bireyler, hareketsiz yaşam tarzını benimser ve alışkanlığa dönüştürür $[7,8]$.

Hareketsizlik kardiyorespiratuar hastalıklar, obezite, diyabet, kanser, kas-iskelet hastalıkları, mental ve ruhsal hastalıklar gibi birçok kronik problem için değiştirilebilir bir risk faktörüdür [9]. Düzenli yapılan fiziksel aktivitenin sağlığın korunmasında ve geliştirilmesinde etkili olduğuna, çeşitli kronik Çalışma öncesi, SDA'nın Türkçe adaptasyonu ve güvenirliği için anketin geliştiricisi olan Dori Rosenberg'ten mail yoluyla izin alındı. Çalışma, İstanbul Ǘniversitesi, İstanbul Tıp Fakültesi Klinik Araştırmalar Etik Kurulu'ndan onay alınarak (2017/270), Helsinki Bildirgesi ilkelerine uygun olarak yürütüldü. Araştırma, NCT03586349 numarası ile ClinicalTrials.gov'a kaydedildi.

Anket çalışmalarında örneklem büyüklüğü belirlenirken sayının değişken sayısının en az 5 katı, hatta 10 katı olması gerektiği genel bir kural olarak kabul edilir. Örneklem büyüklüğü olarak 50 çok zayıf, 100 zayıf, 200 orta, 300 iyi, 500 çok iyi, 1000 hastalıklardan primer ve sekonder korunmada katk1 sağladığına, erken mortalite riskini azalttığına dair kanitlar mevcuttur [5].

Bireylerin fiziksel aktivite düzeylerinin arttırılması için farklı kuruluşlar tarafindan yayınlanan kılavuzlarda, değişen şiddetlerde ve tiplerde aktiviteler önerilmektedir [10]. Ancak uygun aktivite türünün ve şiddetinin belirlenebilmesi için öncelikle bireylerin fiziksel aktivite düzeylerinin belirlenmesi gerektiği vurgulanmaktadır. $\mathrm{Bu}$ amaçla kullanılabilecek direkt ve indirekt kalorimetri, fiziksel aktivite anketleri, fiziksel aktivite kayd1, fizyolojik parametreler, davranış gözlemi, mekanik ve elektronik izleme araçları gibi pek çok yöntem vardır. Bu yöntemlerin birbirine göre avantaj ve dezavantajları mevcuttur [11, 12]. Anketler, aktivitelerin süresi ve sıklığının tanımlanabilmesi, geniş bir yaş aralığında kullanılabilmesi, düşük maliyetle ve büyük ölçekli gruplara uygulanabilmesi gibi avantajlara sahiptir.

Literatürde fiziksel aktivite düzeyini ve sedanter davranışları değerlendiren, güvenirlik ve geçerlik çalışmaları yapılmış farklı anketler mevcuttur [1315]. Çalışmamızın amacı kendi kendine cevaplanabilen bir anket olan, Rosenberg ve arkadaşlarının geliştirdiği Sedanter Davranış Anketi'nin (SDA), 18-64 yaş arası sağlıklı bireylerde kültürel adaptasyonunu ve Türkçe versiyonunun güvenirlik çalışmasını yapmaktır [16].

\section{Materyal ve Metot}

mükemmel bir say1 olarak bildirilmiştir [17]. Çalıştığımız SDA anketinde toplamda 22 madde bulunmaktadır. Değişken sayısını temel aldığımızda her bir madde için 10 kişi dahil ederek örneklem büyüklüğü 220 (orta) olarak belirlenmiştir. Türkçe okuma-yazma veya anlama problemi olmayan 18-64 yaş arası sağlıklı bireyler çalışmaya dahil edilirken, son 6 ayda fiziksel aktiviteleri kısıtlayan şiddetli travma geçirmiş olanlar, ambulasyonu kısitlayan/engelleyen ortopedik, nörolojik, kardiyovasküler problemlere sahip olanlar çalışma dışı bırakıldı. 
Çalışmaya dahil edilen katılımcılar, çalışmanın amacı ve yapılacak değerlendirmeler hakkında bilgilendirildi. Katılımcılardan araştırmaya gönüllü olarak katıldıklarına dair imzalı onam formu alındı. Katılımcıların boy, kilo, eğitim düzeyleri, spor alışkanlıkları gibi sosyodemografik bilgileri, hazırlanan bir form ile toplandı. Çalışmaya dahil edilen tüm katılımcılardan Sedanter Davranış Anketi ve Uluslararası Fiziksel Aktivite Anketi Kisa Formu'nu doldurmaları istendi.

Sedanter Davranış Anketi (SDA), normal bir hafta içi ve hafta sonu gününde, 9 sedanter davranışı ("TV izlemek, bilgisayar/video oyunları oynamak, oturarak radyo/kaset veya CD'den müzik dinlemek, oturarak telefonla konuşmak, evrak işi veya bilgisayar çalışması yapmak, oturarak kitap veya dergi okumak, bir müzik aleti çalmak, sanatsal işler veya el işleri yapmak, araba, otobüs veya trene binmek/sürmek") gerçekleştirirken harcanan süreyi değerlendirmek için geliştirilmiş bir ankettir. Anketin "Hiçbiri", "15 dakika veya daha az", "30 dakika", "1 saat", "2 saat", "3 saat", "4 saat", "5 saat", "6 saat veya daha fazla" olmak üzere dokuz farklı yanıt seçeneği bulunmaktadır. Skorlama öncesi işaretlenmiş olan her davranış için harcanan süreler saate dönüştürülür (Örneğin 15 dakikalık bir yanıt 0,25 saat olarak kaydedilir). Total skor için davranışların saat cinsinden süreleri hafta içi ve hafta sonu olarak ayrı ayrı toplanır. Hafta içi ve sonu için ortalama sedanter davranış sürelerinin elde edilmesi için hafta içine ait total süre 5 ile, hafta sonuna ait total süre de 2 ile çarpılır. Hafta içi ve hafta sonu sedanter davranışlar için harcanan toplam süre hesaplanırken 24 saat/gün'den yüksek skorlar 24 saat/gün'e indirgenerek kaydedilir.

Anketin fibromiyalji tanılı yetişkinlerde geliştirilen İspanyolca adaptasyonunda değerlendirmelere 2 madde ("aileniz ve arkadaşlarınızla oturarak vakit geçirmek, uzanmak ve dinlenmek") daha eklenmiştir. Anketlerin doğru ve sık kullanımı, kültürle ve dille olan uyumla ilişkilidir [18]. Çalışmamızda, eklenen bu 2 sorunun toplumumuz için de uygun olduğu görüşüne varılarak Türkçeye adaptasyonda anketin 11 maddelik İspanyol versiyonunun kullanılmasına karar verildi [19].

Uluslararası Fiziksel Aktivite Anketi Kisa Formu (UFAA-KF), son 7 gündeki insanların günlük yaşamlarının bir parçası olarak yaptıkları fiziksel aktivitelerin yoğunluğunu ve süresini değerlendirmek için kullanılır. Ankette, 3 farklı şiddetteki fiziksel aktivitenin süre ve frekansı ile oturularak geçirilen süre kaydedilir: 1) Şiddetli aktivite (8 MET), 2) Orta şiddetli aktivite (4 MET), 3) Yürüme (3,3 MET). Aktivite şiddeti, günü ve süresi çarpılarak bir skor elde edilir ve oturma süresi hariç 3 aktivitenin MET-dakika/hafta cinsinden değeri toplanarak total skor elde edilir (Örnek: 4,0 MET $x$ aktivite gün $\mathrm{x}$ aktivite süresi (dakika olarak) orta yoğunluklu aktivite toplam MET skoruna eşittir). Total puana göre aktivite düzeyi inaktif
(<600 MET-dk/hafta), minimal aktif (minimum 600 MET-dk/hafta ve <3000 MET-dk/hafta) ve aktif (>3000 MET-dk/hafta) olarak gruplandırılır [13].

Türkçe SDA'nın adaptasyonu beş aşamada gerçekleştirildi [20]. Birinci aşamada anket, İngilizcesi ileri seviyede olan iki akademisyen tarafından birbirlerinden bağımsız olarak Türkçeye çevrildi. İkinci aşamada oluşturulan her iki ön çeviri birbiriyle karşılaştırılarak, çevirilerdeki kavramsal hatalar ve tutarsızlıklar düzeltilerek tek bir anket oluşturuldu. Üçüncü aşamada oluşturulan tek anket, ana dili İngilizce olan bir kişi tarafindan tekrar İngilizceye çevrildi. Dördüncü aşamada çeviri ile orijinal anket karşılaştırıldı. Daha önce yapılan 2 ön çeviriyle birlikte son çeviri karşılaştırıldı. Beşinci aşamada çevirilerin harmonizasyonu yapıldıktan sonra oluşturulan son anket hedef popülasyondaki 5 kişiye pilot olarak uygulandi. Kişiler tarafından yapılan öneriler ve düzeltmeler sonrasinda anlaşılmayan bir yer olmadığına karar verilerek, anket nihai formuna getirildi. Çalışmaya dahil edilen 220 katılımc1, nihai hale getirilen SDA'y1 ve UFAA'nın kısa formunu doldurdu. Güvenirlik analizi (test-retest) için ilk değerlendirmeden 7 gün sonra katılımcılardan SDA'y1 tekrar doldurmaları istendi.

\subsection{Istatistiksel Analiz}

Elde edilen verilerin analizinde SPSS 24.0 paket programı kullanıldı ve $\mathrm{p}<0,05$ istatistiksel olarak anlamlı kabul edildi. Demografik veriler tanımlayıcı testlerle analiz edilirken, kolmogorov smirnov testi ile analiz edilen ve normal dağılan veriler frekans, ortalama değer ve standart sapma olarak gösterildi.

Anketin ölçüte dayalı ve yapısal geçerliliğinin analizi için katılımcılardan ilk değerlendirmede SDA ile eş zamanlı benzer ölçek olan UFAA kısa formunun doldurulması istendi. Toplam UFAA-KF ve UFAA-KF oturma bölümüyle SDA arasındaki ilișki Pearson korelasyon analizi ile incelendi. Korelasyon katsayıs1 <0,25 "zayıf", 0,25-0,50 "zayıf-orta", $0,50-0,75$ orta-iyi ve >0,75 iyimükemmel ilişki olarak yorumlandı [19].

Çalışmamızda güvenirliğin değerlendirilmesinde anketin iç tutarlılı̆̆1 ve kararlılığ incelendi. Anketin iç tutarlılığının testinde $\% 95$ güven aralığında (confidence interval (CI)) cronbach alfa katsayisı hesaplandi. Anketteki maddelerin arasındaki homojenliği gösteren Cronbach alfa katsayısı için $<0,50$ kabul edilemez, 0,50-0,59 zayıf, 0,60-0,69 kabul edilebilir, 0,70-0,89 iyi, $\geq 0,90$ mükemmel olarak kabul edildi [21]. İlk verilerin toplanmasından 7 gün sonra aynı katılımcılardan SDA'nın tekrar doldurulması istendi ve veriler kararlılık için testretest yöntemiyle (Intraclass Correlation Coefficient (ICC), \%95 CI) analiz edildi. Güvenirlik sınıflandırmasına göre ICC değeri için $\leq 0,40$ "zayıf", 0,41-0,60 "orta", $0,61-0,80$ "iyi" ve $\geq 0,81$ "mükemmel" güvenirlik olarak yorumland1 [22]. 
Tablo 1. Katılımcıların sosyodemografik özellikleri

\begin{tabular}{|l|c|}
\hline & Ortalama \pm Standart Sapma \\
\hline Yaş (yıl) & $30,86 \pm 11,01$ \\
\hline VKİ (kg/m $\mathbf{m}^{\mathbf{2}}$ & $23,46 \pm 4,16$ \\
\hline Cinsiyet & Frekans (\% Yüzde) \\
\hline Kadın & $136(\% 61,8)$ \\
\hline Erkek & $84(\% 38,2)$ \\
\hline Eğitim Düzeyi (Mezun) & Frekans (\%Yüzde) \\
\hline İkokul & $8(\% 3,6)$ \\
\hline Ortaokul & $8(\% 3,6)$ \\
\hline Lise & $56(\% 25,5)$ \\
\hline Üniversite & $103(\% 46.8)$ \\
\hline Lisansüstü & $45(\% 20,5)$ \\
\hline Meslek & Frekans (\%Yüzde) \\
\hline Ev Hanımı & $8(\% 3,6)$ \\
\hline Memur & $13(\% 5,9)$ \\
\hline Emekli & $8(\% 3,6)$ \\
\hline Öğrenci & $106(\% 48,2)$ \\
\hline Diğer & $80(\% 36,4)$ \\
\hline VKİ: Vücut kütle indeksi & \\
\hline
\end{tabular}

SDA'nın ölçüte dayalı yapısal geçerliliği değerlendirildiğinde SDA-Hİ (ortalama 12,22 $\pm 4,97$ saat/hafta içi), HS (ortalama $12.57 \pm 4.68$ saat/hafta sonu) ve toplam süreleri (ortalama 24,79 $\pm 8,86$ saat/hafta) ile UFAA-KF oturma süresi (ortalama $7,12 \pm 3,15$ saat/hafta) arasinda zayıf korelasyon tespit edildi. SDA ve UFAA-KF korelasyonu yalnızca orijinal İngilizce versiyonunda yer aldığından, çalışmamızdaki toplam skorların geçerlik sonuçları orijinal çalışmayla karşılaştırmalı olarak Tablo 2'de verildi.

Tablo 2. SDA ile UFAA-KF korelasyonu

\begin{tabular}{|c|c|c|}
\hline & $\begin{array}{c}\text { Güncel Çalışma } \\
(\mathbf{1 1} \text { madde })\end{array}$ & Rosenberg D. ve ark. (16) \\
\hline Toplam SDA-HI & UFAA-KF-Oturma Süresi & UFAA-KF-Oturma Süresi \\
\hline Toplam SDA-HS & $\mathrm{r}=0,254$ & $\mathrm{r}=0,24$ \\
& $\mathrm{p}<0,001^{*}$ & $\mathrm{p}<0,001^{*}$ \\
\hline Toplam SDA & $\mathrm{r}=0,231$ & $\mathrm{r}=0,38$ \\
& $\mathrm{p}=0,001^{*}$ & $\mathrm{p}<0,001^{*}$ \\
\hline & $\mathrm{r}=0,265$ & $\mathrm{r}=0,31$ \\
& $\mathrm{p}<0,001^{*}$ & $\mathrm{p}<0,001^{*}$ \\
\hline
\end{tabular}

SDA-Hİ: Sedanter Davranış Anketi- Hafta İçi, SDA-HS: Sedanter Davranış Anketi- Hafta Sonu, UFAA-KF: Uluslararası Fiziksel Aktivite Anketi Kisa Formu, r: Pearson korelasyon katsayıs1, *p<0,05

Güvenirlik analizinde birinci değerlendirme sonunda elde edilen anket ifadelerinin $(n=22)$ iç tutarlılığ incelendiğinde Cronbach alfa katsayısı 0,588 (\%95 CI; 0,505-0,663) olarak bulundu. Test-retest değerlendirmesinde ilk ölçümler ile 2. ölçümler arasinda 0,83 ICC $(\% 95 \quad \mathrm{CI} ; 0,78-0,87)$ ile mükemmel güvenirlik tespit edildi. Elde edilen sonuçların SDA'nın diğer adaptasyonlarıyla karşılaştırılması Tablo 3'te gösterildi.
Anketin hafta içi ve hafta sonu bölümlerindeki maddelerin 1. ve 2. ölçümlere ait skorlarının güvenirlik ve korelasyon katsayıları \%95 CI aralığında Tablo 4'te gösterildi. Hafta içi ve hafta sonu "Oturarak telefonla konuşmak" maddesi hariç tüm maddelerin ICC değerleri ve korelasyon katsayıları istatistiksel olarak orta-mükemmel arası bulundu $(\mathrm{p}<0,05)$. 
Tablo 3. Anketin test-retest sonuçlarının versiyonları arasında karşılaştırılması

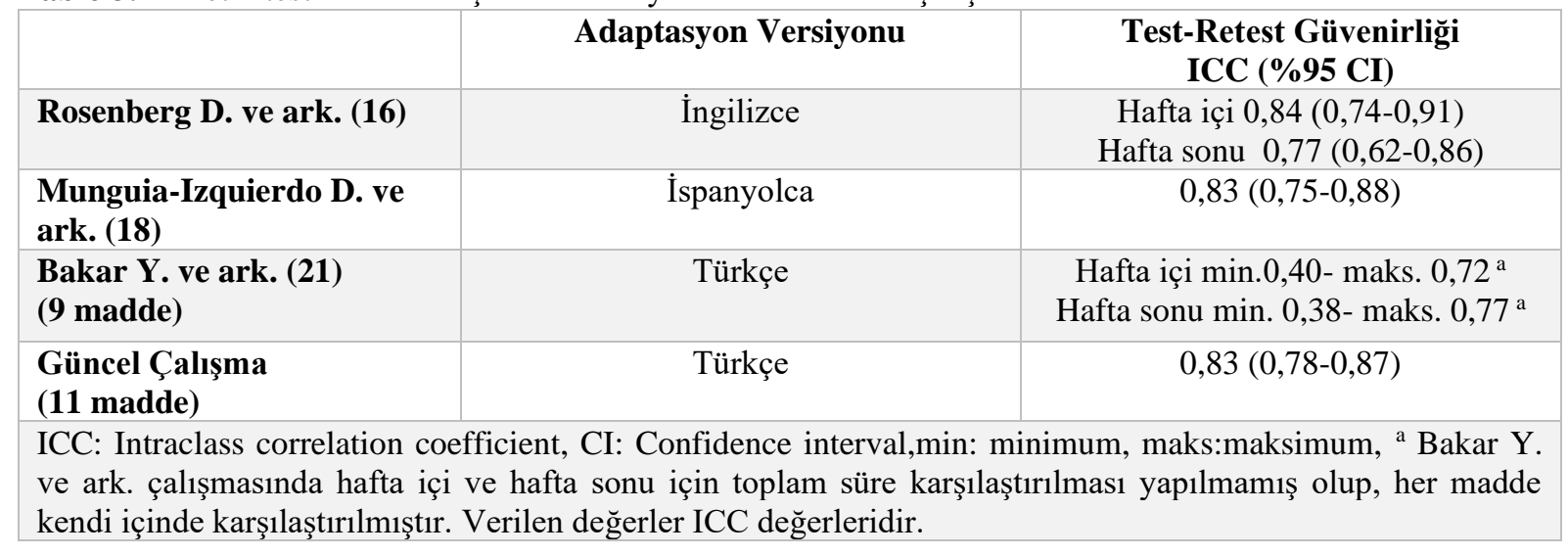

\subsection{Tartışma}

Sedanter davranışlar sırasında harcanan süreler son on yılda önemli oranda artış göstermiştir ve artışının devam etmesi öngörülmektedir. Sağlıkla ilişkili birçok parametreyi olumsuz etkileyen sedanter davranışlar, özellikle yetersiz fiziksel aktiviteye sahip bireylerde sağllğ 1 tehdit eden bir unsur olarak kabul edilmektedir [23]. Sağlığı olumsuz etkileyen ve artan sedanter davranış sürelerinin geniş popülasyonlarda saptanabilmesi ve bu alanda kaliteli çalışmaların ortaya konulabilmesi için sedanter geçirilen süreleri değerlendiren, maliyeti düşük ölçüm araçlarına ihtiyaç vardır. Sedanter davranışların değerlendirilmesinde literatürde en sık hata riski düşük ve objektif olan akselerometreler, pedometre, inklinometre gibi cihazların yanı sira UFAA gibi kendi kendine cevaplanan (self-report) anketler de kullanılmaktadır [11]. Ancak cihazların hareketsizliği ve sedanter davranışların tipini ayırt etme yeteneğinin olmaması, yaygın kullanılan anketlerden olan ve temelde fiziksel aktiviteyi değerlendiren UFAA'nın sedanter davranışları yalnızca tek bir maddeyle (genel oturma süresi) sorgulayarak belirlemesi, davranış spesifik verilerin elde edilebilmesini ve uygun stratejilerin planlanabilmesini kısitlamaktadır. 2010 yılında geliştirilen, 9 farklı sedanter davranışları sorgulayan SDA için araştırmacılar sedanter davranışlara dair yeni seçenekler oluştukça anketin değiştirilmesi gerektiğini vurgulamıştır [16]. Bu bağlamda çalışmamızda, Bakar ve arkadaşlarının ofis çalışanlarında 9 soruluk versiyonunu Türkçeye adapte ettiği SDA'nın, İspanyolca versiyonunda yer alan artı iki soruluk versiyonunun 18-64 yaş arası sağlıklı erişkinlerde Türkçe geçerlik ve güvenirliğini araştırmayı amaçladık.

Anketin geçerlik analizinde, daha çok yeni geliştirilen ve alt bölümlerden oluşan anketlerin analizinde kullanılan faktör analizi yerine, İngilizce ve 9 soruluk Türkçe versiyonlarında da olduğu gibi, benzer ölçekle korelasyon tercih edilmiştir [16, 24, 25]. SDA için güvenirlik değerlendirilmesinde ise anketin tekrarı yöntemi (test-retest) ve iç tutarlılık katsayıları hesaplanmıştır. Bununla birlikte SDA sağlıklı popülasyona uygulandığından ve bireylerin kendi kendini değerlendirmesine dayalı olduğundan, ölçücü güvenirliği için puanlama tutarlılı̆̆ (interrater-intrarater) değerlendirmesine gerek duyulmamıştır.

Orjinal anketin geliştiricisi Rosenberg ve arkadaşları aşırı kilolu yetişkinlerde yaptıkları çalışmalarında SDA ile UFAA-KF oturma bölümü arasında zayıf korelasyon olduğunu bildirmiştir [16]. Çalışmamızda da orjinaline benzer olarak iki anket arasında zayıf bir ilişki ve yapısal geçerlik olduğu tespit edildi. Bakar ve arkadaşları ise çalışmalarında SDA'nın toplam skoru yerine anketin her maddesinin UFAA-KF oturma parametreleri ile ilişkisini incelemiş ve yalnızca hafta içi "Oturarak telefonla konuşmak" ile "Evrak işi/bilgisayar çalışması yapmak", hafta sonu ise "Oturarak telefonla konuşmak" ile "Araç kullanmak/ yolculuk yapmak" maddeleri arasında istatistiki olarak zayıf bir korelasyon olduğunu, diğer maddelerde ise iki anket arasında korelasyon olmadığını bildirmiştir [25]. Bulgularımız doğrultusunda UFAA-KF'nin yalnızca son bir haftanın normal bir günündeki ortalama oturma süresini sorgulaması, SDA'nın ise spesifik olarak normal bir hafta içi ve hafta sonu gününde 11 farklı sedanter davranışta harcanan süreyi sorgulaması nedeniyle iki anketin düşük korelasyon, dolayısıyla SDA'nın zayıf yapısal geçerlik gösterdiği düşüncesindeyiz. Ankette sorgulanan spesifik sedanter aktiviteler bireylerin hatırlamasını kolaylaştırarak, daha fazla düşünmesine ve kognitif süreçlerin devreye girmesine neden olur [16]. Bu sebeplerle çalışmamızda da olduğu gibi UFAAKF'ye kıyasla SDA, daha yüksek sedanter sürelerin kaydedilebilmesine olanak sağlar. Ayrıca İngilizce ve İspanyolca versiyonlarında aktivite süresini objektif olarak değerlendiren akselerometre ile anketin ters ilişkisine bakılmış ve anlamlı bir ilişki bulunamamıştır. Araştırmacılar, bunun akselerometrenin yalnızca hareket edilen süreleri kaydetmesinden, otururken ve ayakta hareketsiz geçirilen süreleri ayırt edememesinden kaynaklanabileceğini öne sürmüştür [16, 19]. Yapılan bir meta-analizde, sedanter davranış 
Tablo 4. SDA madde ve total skorlarının test-retest sonuçları

\begin{tabular}{|c|c|c|c|c|c|c|c|c|}
\hline \multirow{2}{*}{ SDA } & \multicolumn{4}{|l|}{ Hafta İçi } & \multicolumn{4}{|l|}{ Hafta Sonu } \\
\hline & $\begin{array}{l}\text { 1. Ölçüm } \\
\text { (saat/gün) } \\
\text { Ort } \pm \text { SS }\end{array}$ & $\begin{array}{l}\text { 2. Ölçüm } \\
\text { (saat/gün) } \\
\text { Ort } \pm \text { SS }\end{array}$ & $\begin{array}{l}\text { ICC } \\
(\% 95 \\
\text { CI })\end{array}$ & $\begin{array}{l}\text { Pearson } \\
\text { rho } \\
(\% 95 \\
\text { CI })\end{array}$ & $\begin{array}{l}\text { 1. Ölçüm } \\
\text { (saat/gün) } \\
\text { Ort } \pm \text { SS }\end{array}$ & $\begin{array}{l}\text { 2. Ölçüm } \\
\text { (saat/gün) } \\
\text { Ort } \pm \text { SS }\end{array}$ & $\begin{array}{l}\text { ICC } \\
(\% 95 \\
\text { CI })\end{array}$ & $\begin{array}{l}\text { Pearson } \\
\text { rho } \\
(\% 95 \\
\text { CI })\end{array}$ \\
\hline TV izlemek & $1,13 \pm 1,18$ & $0,97 \pm 1,03$ & $\begin{array}{l}0,866 \\
(0,825- \\
0,897)\end{array}$ & $\begin{array}{l}0,770^{*} \\
(0,702- \\
0,834)\end{array}$ & $1,54 \pm 1,38$ & $1,49 \pm 1,34$ & $\begin{array}{l}0,859 \\
(0,816- \\
0,892)\end{array}$ & $\begin{array}{l}0,753^{*} \\
(0,665- \\
0,820)\end{array}$ \\
\hline $\begin{array}{l}\text { Aileyle/arkadaşlarla } \\
\text { oturarak } \\
\text { geçirmek }\end{array}$ & $2,49 \pm 1,59$ & $2,26 \pm 1,47$ & $\begin{array}{l}0,790 \\
(0,726- \\
0,839)\end{array}$ & $\begin{array}{l}0,655^{*} \\
(0,545- \\
0,746)\end{array}$ & $3,25 \pm 1,55$ & $2,89 \pm 1,64$ & $\begin{array}{l}0,798 \\
(0,737- \\
0,845)\end{array}$ & $\begin{array}{l}0,665^{*} \\
(0,558- \\
0,765)\end{array}$ \\
\hline Uzanarak dinlenmek & $1,87 \pm 1,57$ & $1,65 \pm 1,38$ & $\begin{array}{l}0,816 \\
(0,760- \\
0,859)\end{array}$ & $\begin{array}{l}0,695^{*} \\
(0,594- \\
0,779)\end{array}$ & $2,45 \pm 1,70$ & $2,23 \pm 1,54$ & $\begin{array}{l}0,795 \\
(0,733- \\
0,843)\end{array}$ & $\begin{array}{l}0,663^{*} \\
(0,566- \\
0,742)\end{array}$ \\
\hline $\begin{array}{l}\text { Bilgisayar/video } \\
\text { oyunları oynamak }\end{array}$ & $0,53 \pm 1,03$ & $0,43 \pm 0,87$ & $\begin{array}{l}0,819 \\
(0,764- \\
0,861)\end{array}$ & $\begin{array}{l}0,703^{*} \\
(0,496- \\
0,842)\end{array}$ & $0,64 \pm 1,22$ & $0,46 \pm 1,01$ & $\begin{array}{l}0,868 \\
(0,828- \\
0,899)\end{array}$ & $\begin{array}{l}0,780^{*} \\
(0,649- \\
0,877)\end{array}$ \\
\hline $\begin{array}{l}\text { Oturarak müzik } \\
\text { dinlemek }\end{array}$ & $0,72 \pm 1,04$ & $0,61 \pm 0,86$ & $\begin{array}{l}0,817 \\
(0,761- \\
0,859)\end{array}$ & $\begin{array}{l}0,703^{*} \\
(0,544- \\
0827)\end{array}$ & $0,68 \pm 0,99$ & $0,62 \pm 0,85$ & $\begin{array}{l}0,815 \\
(0,759- \\
0,858)\end{array}$ & $\begin{array}{l}0,696^{*} \\
(0,513- \\
0,836)\end{array}$ \\
\hline $\begin{array}{ll}\text { Oturarak } & \text { telefonla } \\
\text { konuşmak } & \end{array}$ & $0,98 \pm 1,30$ & $0,73 \pm 0,77$ & $\begin{array}{l}0,413 \\
(0,234- \\
0,550)\end{array}$ & $\begin{array}{l}0,296^{*} \\
(0,162- \\
0,442)\end{array}$ & $0,84 \pm 0,99$ & $0,88 \pm 1,81$ & $\begin{array}{l}0,291 \\
(0,076- \\
0,457)\end{array}$ & $\begin{array}{l}0,202 * * \\
(0,043- \\
0,714)\end{array}$ \\
\hline $\begin{array}{l}\text { Evrak işi/bilgisayar } \\
\text { çalışması yapmak }\end{array}$ & $1,74 \pm 2,34$ & $1,63 \pm 2,25$ & $\begin{array}{l}0,927 \\
(0,904- \\
0,944)\end{array}$ & $\begin{array}{l}0,864^{*} \\
(0,794- \\
0,923)\end{array}$ & $0,72 \pm 1,29$ & $0,73 \pm 1,31$ & $\begin{array}{l}0,787 \\
(0,722- \\
0,837)\end{array}$ & $\begin{array}{l}0,649^{*} \\
(0,478- \\
0,792)\end{array}$ \\
\hline $\begin{array}{l}\text { Oturarak kitap vb. } \\
\text { okumak }\end{array}$ & $0,86 \pm 0,96$ & $0,82 \pm 1,01$ & $\begin{array}{l}0,770 \\
(0,700- \\
0,824)\end{array}$ & $\begin{array}{l}0,627^{*} \\
(0,381- \\
0,787)\end{array}$ & $1,00 \pm 0,99$ & $0,95 \pm 1,08$ & $\begin{array}{l}0,798 \\
(0,736- \\
0,845)\end{array}$ & $\begin{array}{l}0,666^{*} \\
(0,502- \\
0,798)\end{array}$ \\
\hline Müzik aleti çalmak & $0,03 \pm 0,13$ & $0,03 \pm 0,15$ & $\begin{array}{l}0,843 \\
(0,795- \\
0,880)\end{array}$ & $\begin{array}{l}0,738^{*} \\
(0,398- \\
0,915)\end{array}$ & $0,03 \pm 0,15$ & $0,04 \pm 0,20$ & $\begin{array}{l}0,887 \\
(0,852- \\
0,913)\end{array}$ & $\begin{array}{l}0,826^{*} \\
(0,563- \\
0,963)\end{array}$ \\
\hline $\begin{array}{l}\text { Sanatsal işler/ el işi } \\
\text { yapmak }\end{array}$ & $0,26 \pm 0,81$ & $0,15 \pm 0,45$ & $\begin{array}{l}0,578 \\
(0,450- \\
0,676)\end{array}$ & $\begin{array}{l}0,481^{*} \\
(0,234- \\
0,707)\end{array}$ & $0,26 \pm 0,71$ & $0,17 \pm 0,44$ & $\begin{array}{l}0,701 \\
(0,610- \\
0,771)\end{array}$ & $\begin{array}{l}0,604^{*} \\
(0,403- \\
0,811)\end{array}$ \\
\hline $\begin{array}{l}\text { Araç kullanmak/ } \\
\text { yolculuk yapmak }\end{array}$ & $1,6 \pm 1,42$ & $1,69 \pm 1,49$ & $\begin{array}{l}0,778 \\
(0,710- \\
0,830)\end{array}$ & $\begin{array}{l}0,637^{*} \\
(0,503- \\
0,747)\end{array}$ & $1,16 \pm 1,15$ & $1,21 \pm 1,15$ & $\begin{array}{l}0,747 \\
(0,670- \\
0,806)\end{array}$ & $\begin{array}{l}0,596^{*} \\
(0,420- \\
0,731)\end{array}$ \\
\hline Toplam & $12,22 \pm 4,97$ & $10,96 \pm 4,49$ & $\begin{array}{l}0,831 \\
(0,779- \\
0,870)\end{array}$ & $\begin{array}{l}0,714^{*} \\
(0,620- \\
0,788)\end{array}$ & $12,57 \pm 4,68$ & $11,67 \pm 4,65$ & $\begin{array}{l}0,761 \\
(0,688- \\
0,817)\end{array}$ & $\begin{array}{l}0,614^{*} \\
(0,487- \\
0,733)\end{array}$ \\
\hline
\end{tabular}

SDA: Sedanter Davranıs Anketi, Ort: Ortalama, SS: Standart Sapma, ICC: Intraclass corelation coefficient, CI: Confidence interval,

Pearson rho: Pearson korelasyon katsayıs1, ${ }^{*} \mathrm{p}<0,001,{ }^{* *} \mathrm{p}=0,003$.

sürelerinin direkt ölçümünde popüler hale gelen ve geçerli olan akselerometre ve inklinometrelerin yüksek maliyetleri, cihaz ve kaynak kisitllilı̆ cihazların değerlendirilen kişi üzerinde kalması gereken sürenin uzunluğu, geniş örneklemlerde uygulanma kısitlllığı gibi dezavantajlara sahip olduğu bildirilmiştir [26]. Bununla birlikte kendi kendini değerlendirmeye dayalı ölçekler ve anketler geniş çaplı ulusal değerlendirme sistemleri ve araștırmalar için hala en pratik ve detaylı sedanter davranış bilgisi sağlayan yöntemler olarak kabul edilmektedir. $\mathrm{Bu}$ yöntemlerin aksine cihazlar, davranıșın tipi, alanı gibi konularda veri sağlamakta eksik kalmaktadır [11].

SDA'nın diğer versiyon çalışmalarında iç tutarlılık değerlendirmesi yapılmamıștır. Çalışmamızda ise geçerliliğe ek olarak anketin iç tutarlılığı da değerlendirilmiş ve 0,588 olarak bulunmuştur. $\mathrm{Bu}$ bulgu anketin hafta içi ve hafta sonu olarak ayrılan iki bölümünde de yer alan soruların aynı olmasına bağlı olarak toplam soru sayısının 2 katına çıkmasından kaynaklanmış olabilir.
Test-retest için tercih edilen zaman aralıkları değerlendirilen tutarlılık için önemlidir. Genel olarak test-retest için 3-7 gün arasındaki süreler kabul görmektedir [18]. SDA'nın diğer versiyon çalıșmalarında bu süre 7 gün olarak belirlenmiștir. Çalışmamızda da anketin toplam skoru için 7 gün arayla yapılan iki ölçümü arasındaki tutarlılı̆̆ı/kararlılığı İngilizce ve İspanyolca versiyonlarına benzer olup, çalışmamızda da mükemmel olarak yorumlandı. Bakar ve arkadaşları çalışmalarında anket maddelerinin tutarlılığını ayrı ayr1 inceleyerek, kabul edilemez ve iyi arasinda bulmuştur (SDA hafta içi; ICC 0,408 (müzik aleti çalmak)-0,705 (sanatsal işler/ el işi yapmak) arasında, hafta sonu; 0,388 (sanatsal işler/el işi yapmak)-0,771 (oturarak kitap, dergi okumak) [25]. Çalıșmamızda her maddenin test-retest (ICC) ve korelasyon katsayıları ayrıca incelendiğinde orta ile yüksek arasında olup, İngilizce ve İspanyolca versiyonlarında belirlenen değerlere benzerdi. 
Hafta içi ICC değerleri 0,413 (oturarak telefonla konuşmak)-0,927 (evrak işi/bilgisayar çalışması yapmak) arasında değişirken, hafta sonu 0,291 (oturarak telefonla konuşmak)-0,887 (müzik aleti çalmak) arasında değişmekteydi. "Oturarak telefonla konuşma" maddesi için tespit edilen düşük tutarlılık ve korelasyon katsayısı, günümüzde telefonların, kulaklıkların kablosuz ve taşınabilir olma özellikleri sayesinde hareket halinde ve diğer günlük işler esnasında kullanılabilmeleriyle ilişkili olabilir. İş ve okul ortamlarında harcanan çalışma sürelerinin hafta içi günlerinin büyük bir kısmını kapladığı göz önünde bulundurularak "Evrak işi/bilgisayar çalışması yapmak" maddesinin hafta içinde tespit edilen yüksek tutarlılığı ve korelasyonu açıklanabilir.

Çalışmamızda en fazla süre harcanan ilk üç sedanter davranış sırasıyla hafta içinde "Aileyle/arkadaşlarla oturarak vakit geçirmek", "Uzanarak dinlenmek", "Evrak işi/bilgisayar çalışması yapmak" iken, hafta sonunda ise "Aileyle/arkadaşlarla oturarak vakit geçirmek", "Uzanarak dinlenmek" ve "TV izlemek" idi. Hem hafta içi hem hafta sonu en düşük süreye sahip sedanter davranışın ise "Müzik aleti çalmak" olduğu görüldü.

Yaş ortalamalarına bakıldığında çalışmaya dahil edilen katılımcılar genç erişkin grupta yer almaktadır. $\mathrm{Bu}$ grubun sosyalleşme ihtiyacının yüksek oluşu nedeniyle hem hafta içi hem hafta sonu aile ve arkadaşlarla oturularak geçirilen süreler en yüksek bulunmuş olabilir. Çalışma sonucunda edilen bu bilgi doğrultusunda sosyalleşme için sedanter olarak harcanan zamanın aktif sosyalleşmeye dönüştürülmesi için stratejiler geliştirilmesi gerekmektedir. Hafta içi bilgisayar/evrak işleriyle harcanan süre hafta sonu bir fiziksel aktiviteye dönüşmek yerine TV izlenerek harcanmıştır. Bu bulgular, sağlığın korunabilmesi ve geliştirilebilmesi için planlanacak stratejilere, sedanter davranışlarla kaybedilen sürelerin, başka bir sedanter davranışa dönüşmesinin önlenmesi ve fiziksel aktiviteye dönüştürülmesi gerektiği yönünde kıymetli bilgiler sağlamaktadır.

Müzik aleti çalmak özel beceri-yetenek ve eğitim gerektirdiğinden en düşük süreye sahip sedanter davranış olabilir. $\mathrm{Bu}$ bilginin daha detaylı araştırılabilmesi için SDA'nın farklı meslek gruplarında geçerlik ve güvenirlik çalışması yapılmalidir.

SDA, sedanter davranışları 11 madde ile tek tek irdelerken, bireyler bu davranışlarda harcadıkları süreleri genel sorularla değerlendirme yapan anketlere kıyasla daha iyi hatırlar ve sedanter geçirilen süreler ve tipleri daha doğru değerlendirilebilir.

Sedanter davranışların ve dağılımının belirlenmesi özellikle fiziksel aktivite önerileri veya stratejileri açısından önemli bilgiler sağlayabilir. Böylece fiziksel aktivite düzeyini arttırmak için kişiye özel (örneğin aileyle/arkadaşlarla oturarak vakit geçirmek yerine aileyle/arkadaşlarla buluşarak bowling/bilardo, paint ball gibi aktivitelere gitmek) daha etkin yaklaşımlar benimsenebilir. UFAA benzeri anketlerde ve cihazlarda özgüllük düşük olduğundan, gelecek çalışmalarda bu yöntemlere ek olarak SDA'nın kullanılması sedanter davranışlara dair daha değerli ve tamamlayıcı bilgilerin elde edilmesini sağlar.

\subsection{Limitasyonlar}

Çalışmamızda, sedanter geçirilen süreyi objektif değerlendiren ve orijinal çalışmada da yer alan akselerometre veya benzeri bir cihaz kullanılamamıştır.

\section{4 Öneriler}

Sedanter davranış yönelimleri zaman ve teknoloji ile değişim göstermektedir. Bu değişimlere bağlı olarak anketin de güncellenmesi gerekir. Örneğin TV yerine, filmler, diziler ve videolar internet üzerinden farklı platformlarda izlenmektedir, müzik de radyolar, kasetler yerine çoğunlukla telefondan, kablosuz cihazlardan dinlenmektedir. Günümüzde teknolojinin gelişmesiyle birlikte kablosuz kullanılabilen aksesuarların da artışıyla telefon görüşmeleri, müzik dinlemek hareket ederken ya da farklı işleri yaparken de gerçekleştirilebilir hale gelmiştir. Bu gelişmelerle birlikte "sosyal medya kullanımı" adında bir kavram ortaya çıkmış ve sosyal medya kullanımına ayrılan süre zaman içinde artarak, bireylerin hareketsiz kalmalarına neden olmuştur. $\mathrm{Bu}$ gelişmeler ve değişimler karşısında adapte edilen ankete "sosyal medya kullanmak" gibi sorular eklenerek veya var olan sorular revize edilerek SDA'nın güncel ve uygun kalması sağlanabilir.

\section{Sonuc}

Eklenen iki soruyla genişletilen SDA, 18-64 yaş arası sağlıklı erişkinlerde kolayca uygulanabilen, yapısal geçerliliğinin geliştirilmesine ihtiyaç duyan ancak güvenirliği yüksek, kapsamlı bir ankettir. SDA, sedanter davranışların farklı alanları ve tipleri hakkında daha net bilgilerin elde edilebilmesini, farklı popülasyonlarda bu davranışlar üzerine daha spesifik çalışmalar ortaya konulabilmesini ve müdahalelerin planlanabilmesini sağlayabilir. Önceki versiyon çalışmalarında da önerildiği gibi, SDA'nın farklı popülasyonlara, yaş gruplarına, gelişmelere ve içinde bulunulan yaşam koşullarına uygun olarak revize edilmesi ve tekrar uyarlanması gerekebilir.

\section{Referanslar}

1.Owen, N, Healy, G.N, Matthews, C.E, Dunstan, D.W, Too much sitting: the population health science of sedentary behavior, Exercise and sport sciences reviews, 2010, 38(3), 105-13.

2.Holtermann, A, Schellewald, V, Mathiassen, S.E, Gupta, N, Pinder, A, Punakallio, A, et al., A practical guidance for assessments of sedentary behavior at work: A PEROSH initiative, Applied ergonomics, 2017, 63, 41-52.

3.Schmid, D, Ricci, C, Leitzmann, M.F, Associations of objectively assessed physical activity and sedentary time with allcause mortality in US adults: the NHANES study, PLoS One, 2015, 10(3), e0119591.

4. Wijndaele, K, Brage, S, Besson, H, Khaw, K.T, Sharp, S.J, Luben, R, et al., Television viewing time independently predicts 
all-cause and cardiovascular mortality: the EPIC Norfolk study, nternational journal of epidemiology, 2011, 40(1), 150-9.

5.von Rosen, P., Dohrn, I. M., Hagströmer, M., Association between physical activity and all-cause mortality: A 15-year follow-up using a compositional data analysis, Scandinavian journal of medicine \& science in sports, 2020, 30(1): p. 100-107.

6. Chau, J.Y, Grunseit, A.C, Chey, T, Stamatakis, E, Brown, W.J, Matthews, C.E, et al., Daily sitting time and all-cause mortality: a meta-analysis, PLoS One, 2013, 8(11), e80000.

7. Nowak, P.F, Bożek, A, Blukacz, M, Physical Activity, Sedentary Behavior, and Quality of Life among University Students, BioMed research international, 2019, 9791281.

8. Bozkuş, T, Türkmen, M, Kul, M, Özkan, A, Öz, Ü, Cengiz, $\mathrm{C}$, Beden eğitimi ve spor yüksekokulu'nda öğrenim gören öğrencilerin fiziksel aktivite düzeyleri ile sağlikli yaşam biçimi davranişlarinin belirlenmesi ve ilisskilendirilmesi, International Journal of Sport Culture and Science, 2013, 1(3), 49-65.

9.Zengin Alpözgen, A, Özdinçler, A, Fiziksel aktivite ve koruyucu etkileri: Derleme, Sağlık Bilimleri ve Meslekleri Dergisi, 2016 , 3(1), 66-72.

10. Singh, R, Pattisapu, A, Emery, M.S, US Physical Activity Guidelines: Current state, impact and future directions, Trends in cardiovascular medicine, 2020, 30(7), 407-412.

11. Prince, S.A, Cardilli, L, Reed, J.L, Saunders, T.J, Kite, C, Douillette, K, et al., A comparison of self-reported and device measured sedentary behaviour in adults: a systematic review and meta-analysis, International Journal of Behavioral Nutrition and Physical Activity, 2020, 17(1), 31.

12. Dowd, K.P, Szeklicki, R, Minetto, M.A, Murphy, M.H, Polito, A Ghigo, E, et al., A systematic literature review of reviews on techniques for physical activity measurement in adults: a DEDIPAC study, International Journal of Behavioral Nutrition and Physical Activity, 2018, 15(1), 15.

13. Saglam, M, Arikan, H, Savci, S, Inal-Ince, D, Bosnak-Guclu, M, Karabulut, E, Tokgozoglu, L, International physical activity questionnaire: reliability and validity of the Turkish version, Perceptual and motor skills, 2010, 111(1), 278-284.

14. Kaya Noğay, A.E, Özen, M, Birinci Basamak İçin Fiziksel Aktivite Anketinin Türkçe Uyarlamasının Geçerlilik ve Güvenilirliği, Konuralp Tip Dergisi, 2019, 11(1), 1-8.

15. Karaca, A, Demirci, N, Validity and Reliability of the Adolescent Sedentary Activity Questionnaire (ASAQ) in Adolescents Aged Between 11 and 14, Spor Hekimliği Dergisi, 2019, 54(4), 255266.

16. Rosenberg, D.E, Norman, G.J, Wagner, N, Patrick, K, Calfas, K, J, Sallis, J.F, Reliability and validity of the Sedentary Behavior Questionnaire (SBQ) for adults, Journal of Physical Activity and Health, 2010, 7(6), 697-705.

17. Tavşancıl, E, Tutumların ölçülmesi ve SPSS ile veri analizi, Nobel Yayıncılı, Ankara, 2002.

18. Alaca, N, Frenchay Aktiviteler İndeksinin Türkçe Versiyonunun Psikometrik Özelliklerinin Değerlendirmesi ile Kültürel Adaptasyonu. Sakarya Tip Dergisi, 2020, 10(4), 556-564.

19. Munguia-Izquierdo, D, Segura-Jimenez, V, Camiletti-Moirón, D, Alvarez-Gallardo, I.C, Estévez-López, F, Romero, A, DelgadoFernandez, M, Spanish adaptation and psychometric properties of the Sedentary Behaviour Questionnaire for fibromyalgia patients: the al-Andalus study, Clinical and Experimental Rheumatology, 2013, 31(6 Suppl 79), S22-33.

20. Beaton, D.E, Bombardier, C, Guillemin, F, Ferraz, M.B Guidelines for the process of cross-cultural adaptation of selfreport measures, Spine, 2000 25(24), 3186-3191.

21. Kiliç, S, Cronbach's alpha reliability coefficient, Psychiatry and Behavioral Sciences, 2016, 6(1), 47.

22. Busschaert, C, De Bourdeaudhuij, I, Van Holle, V, Chastin, S.F Cardon, G, De Cocker, K, Reliability and validity of three questionnaires measuring context-specific sedentary behaviour and associated correlates in adolescents, adults and older adults, International Journal of Behavioral Nutrition and Physical Activity, 2015, 12, 117

23. Bakker, E.A, Hartman, Y.A, Hopman, M.T, Hopkins, N.D, Graves, L.E, Dunstan, D.W, et al., Validity and reliability of subjective methods to assess sedentary behaviour in adults: a systematic review and meta-analysis, International Journal of Behavioral Nutrition and Physical Activity, 2020, 17(1), 1-31.

24. Karakoç, F.Y, Dönmez, L, Ölçek geliştirme çalışmalarında temel ilkeler, Tıp Eğitimi Dünyası, 2014, 13(40), 39-49.

25. Bakar, Y, Tugral, A, Ozel, A, Altuntas, Y.D, Yakut, Y, Reliability and Validity of Sedentary Behavior Questionnaire in Turkish Population: Evaluation of Psychometric Properties, Middle East Journal of Rehabilitation and Health, 2018, 5(2), e63576.

26. Prince, S.A, LeBlanc, A.G, Colley, R., Saunders, T.J, Measurement of sedentary behaviour in population health surveys: a review and recommendations, PeerJ Life \& Environment, 2017, 5, e4130.

http://edergi.cbu.edu.tr/ojs/index.php/cbusbed isimli yazarın CBU-SBED başlıklı eseri bu Creative Commons Alınt1-Gayriticari4.0 Uluslararası Lisansı ile lisanslanmıştır.

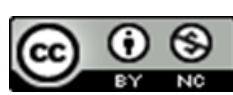

